\title{
Reflexões Epistemológicas sobre o SUS e Atuação do Psicólogo
}

Reflection about Epistemological Dimension of the SUS and Psychologist Performance

Reflexións Epistemológicas del SUS y Actuación del Psicólogo

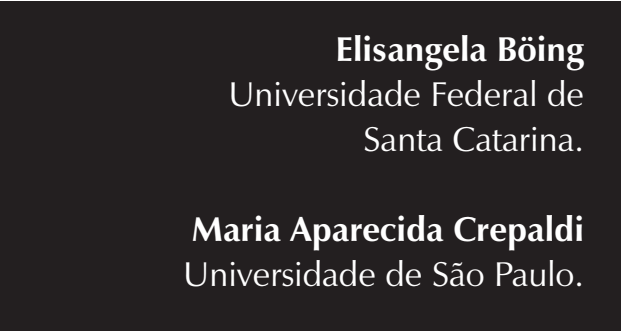

http://dx.doi.org/10.1590 / 1982 - 3703001052013

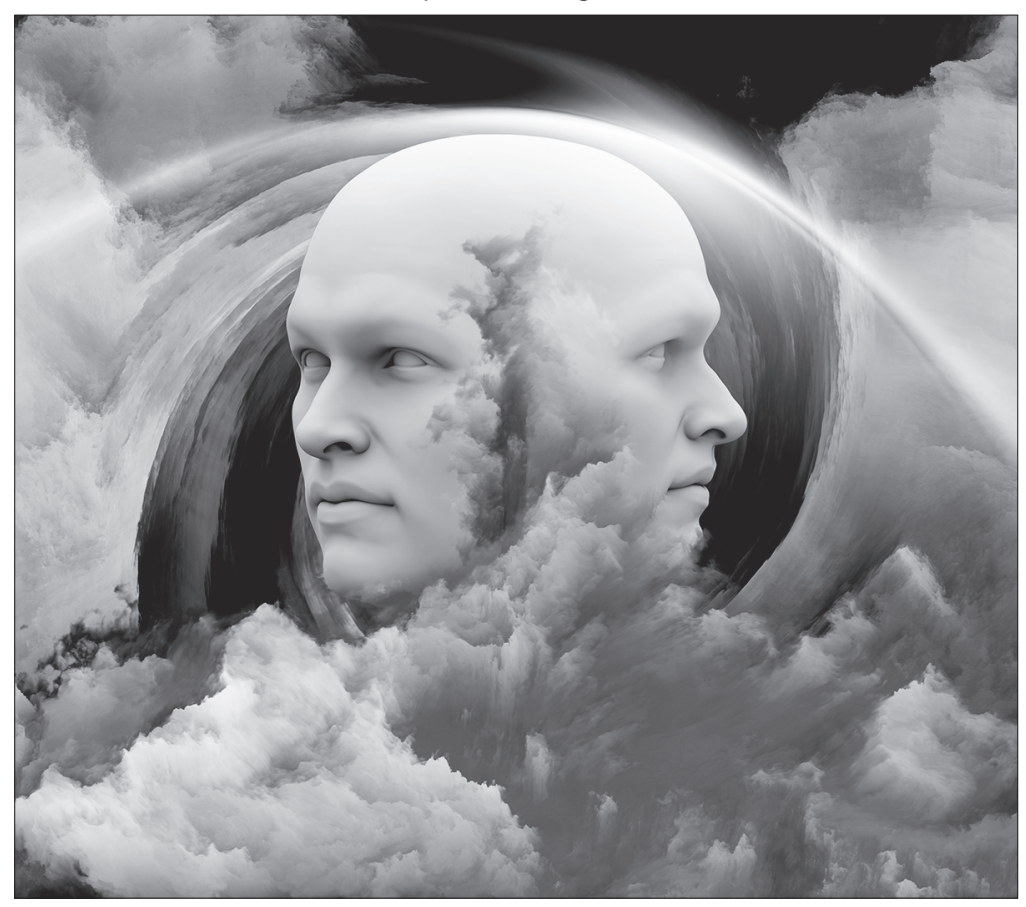


Resumo: O projeto político do Sistema Único de Saúde (SUS) visa à implantação de um sistema público que atenda às necessidades de saúde da população. O SUS é fruto de uma mudança de paradigma, desde a mudança de concepção de saúde, de produção de conhecimento e de práticas de saúde. A efetiva consolidação do SUS depende, em grande parte, da compreensão epistemológica de sua proposta por parte de todos os atores envolvidos: gestores, profissionais de saúde e cidadãos. Com essa compreensão, os profissionais serão capazes de refletir sobre suas práticas, tornando-as condizentes às demandas da saúde coletiva. Nesse sentido, este artigo visa a oferecer subsídios para reflexão a respeito da dimensão epistemológica da proposta do SUS e de uma atuação que concretize a sua consolidação.

Palavras-chave: Epistemologia. Sistema Único de Saúde. Atuação do psicólogo. Política de saúde

Abstract: The political project of the Unified Health System (SUS) aims to implement a public system which attends the health needs of the population. SUS is the result of a paradigm shift, since the change in definition of health, knowledge production and health practices. The effective consolidation of SUS depends largely on the epistemological understanding of its proposal by all stakeholders: managers, health professionals and citizens. With this understanding, professionals will be able to reflect on their practices, making them suitable to public health demands. Thus, this article aims to provide support for reflection on the epistemological dimension of the SUS and actions which implement its consolidation.

Keywords: Epistemology. Single Health System (SUS). Psychologist Performance. Health care policy.

Resumen: El proyecto político del Sistema Único de Salud (SUS) visa a la implantación de un sistema público que atienda a las necesidades de salud de la población. El SUS es fruto de una mudanza de paradigma, desde la mudanza de concepción de salud, de producción de conocimiento y de prácticas de salud. La efectiva consolidación del SUS depende, en gran parte, de la comprensión epistemológica de su propuesta por parte de todos los actores involucrados: gestores, profesionales de salud y ciudadanos. Con esa comprensión, los profesionales serán capaces de reflexionar sobre sus prácticas, tornándolas adecuadas a las demandas de la salud colectiva. En ese sentido, este artículo visa a ofrecer subsidios para reflexión a respecto de la dimensión epistemológica de la propuesta del SUS y de una actuación que concrete su consolidación.

Palabras-clave: Epistemologia. Sistema Único de Salud. Actuación del psicólogo. Política de salud.

O Sistema Único de Saúde (SUS) é resultante do expressivo movimento de reforma sanitária, inserido no movimento mais amplo de redemocratização do país e que teve na VIII Conferência Nacional de Saúde, em 1986, um de seus locus privilegiados para o estabelecimento das grandes diretrizes para a reorganização do sistema de saúde no Brasil. As principais diretrizes do SUS estabelecem um conceito ampliado de saúde, incorporando fatores do meio físico, socioeconômico, cultural e oportunidades de acesso aos serviços de promoção, proteção e recuperação da saúde. A legislação do SUS legitimou o direito de todos às ações de saúde, cabendo, ao governo, garantir esse direito (Andrade, Soares, \& Cordoni, 2001; Brasil, 1990).

São princípios doutrinários do SUS: universalidade, equidade e integralidade. O primeiro consiste na garantia de atenção à saúde, por parte do sistema, a todo cidadão. A equidade objetiva diminuir as desigualdades e consiste no entendimento de que, embora todos tenham direitos aos serviços de saúde, os investimentos e atenção são distribuídos con- 
1. Recuperado de: $<$ http://www.pmf.sc .gov.br/entidades/s aude/index.php?cm $\mathrm{s}=$ populacao\&menu $=0>$. Acesso em: ago. 2012.

2. Recuperado de: $<$ http://cstapera.blogspot.co m.br/>. Acesso em: mar. 2013. forme necessidade de saúde, independentemente do poder aquisitivo do cidadão. $\mathrm{O}$ princípio da integralidade preconiza que as ações de saúde devam voltar-se ao indivíduo, considerando aspectos biológicos, psicológicos, sociais e os contextos de vida, e que as ações devam ser combinadas e voltadas para promoção, prevenção e a recuperação da saúde (Brasil, 1990).

Campos (2007) afirma que o devir do SUS nem sempre aponta para seu fortalecimento e que há evidências de impasses na sua implantação: financiamento insuficiente; atenção primária crescendo, mas em velocidade e com qualidade abaixo da necessária; regionalização e integração entre municípios e serviços quase virtuais; e, ainda, eficácia e eficiência de hospitais e serviços especializados abaixo do esperado. Mais grave que tudo isso, ressalta, é a impressão de que há um desencantamento com o SUS ou, talvez, um descrédito quanto à capacidade para transformar em realidade uma política tão generosa e racional. Esses sinais de crise, segundo o autor, não depõem necessariamente contra as diretrizes centrais do sistema. Isto porque o SUS ainda é uma reforma social incompleta e com implantação heterogênea. Nesse sentido, certamente a irregularidade com que vem interferindo de modo positivo sobre a vida cotidiana da maioria do povo tem contribuído para esse desinteresse.

A recuperação - ou desenvolvimento - de prestígio para o projeto do SUS depende, segundo Campos (2007), de uma tríade complexa. Primeiro, de criar-se um movimento de peso em defesa de políticas de proteção social e distribuição de renda. Segundo, de que se consiga apresentá-lo para a sociedade como uma reforma social significativa e que teria grande impacto sobre o bem-estar e proteção social, indicando, com objetividade, os passos e programas necessários. E terceiro, paradoxalmente, sua legitimidade depende muito de seu desempenho concreto, de sua efetiva capacidade para melhorar as condições de vida e a saúde das pessoas. Nesse caso, segundo o autor, a baixa capacidade de gestão, a "politicagem", tudo depõe contra o SUS, independentemente do potencial sanitário contido em suas promessas.

Para quem já teve a experiência de atuar em serviços de saúde pública fica evidente o desconhecimento da população a respeito da proposta do SUS, sobretudo, que são poucos os profissionais de saúde e gestores que têm a compreensão da dimensão epistemológica da mudança de modelo de atenção preconizada pela legislação do SUS. Essa falta de compreensão mostra-se como um importante entrave na consolidação da mudança de modelo, pois ela depende de uma mudança de paradigma, de visão de mundo, de concepções sobre saúde e doença e das práticas de saúde.

Nesse contexto, este artigo visa a contribuir para uma compreensão epistemológica das diretrizes da saúde pública brasileira e atuação no SUS. Terá como foco a atuação do psicólogo, contudo, as reflexões poderão se estender aos demais profissionais de saúde para (re)pensarem suas concepções, teorias e práticas. O artigo tem por base teórica o pensamento sistêmico enquanto epistemologia, por entender que este não se opõe ao paradigma tradicional da ciência, mas permite sua revisão. Que uma visão segundo seus pressupostos fundamentais permite a compreensão do processo saúde-doença, enquanto um fenômeno complexo. Bem como permite a reflexão sobre uma atuação do psicólogo no setor saúde, condizente aos princípios e diretrizes do SUS.

Por meio de uma reflexão epistemológica referente à transição do paradigma tradicional e do novo paradigma da ciência, será apresentada uma contextualização da temática. Uma breve explanação sobre a evolução do conceito e práticas de saúde e os reflexos da transformação da ciência sobre os mesmos, assim como as implicações para a Psicologia e para a atuação do psicólogo no SUS. 
3. O PSE é um programa interministerial (Ministério da Saúde e Ministério da Educação).
Cabe esclarecer, ainda, o uso de alguns termos ao longo do trabalho para facilitar a compreensão destes. Embora possam ser feitas distinções no uso de algumas terminologias, serão utilizados como sinônimos: epistemologia e paradigma; tradicional e moderno; pensamento sistêmico, novo-paradigma e pós-moderno.

\section{Modelos de compreensão do binômio saúde-doença}

A compreensão a respeito do tema saúde está diretamente relacionada à cultura, ao contexto histórico e às condições concretas de existência, além disso, são as concepções sobre saúde e doença predominantes em uma sociedade que determinam as práticas de saúde adotadas. Um breve resgate histórico, do período final do século XVIII até os dias atuais, permite a visualização da evolução das concepções de saúde e correlação destas com as práticas de saúde. A escolha desse recorte se justifica em virtude de que as concepções e práticas de saúde desenvolvidas nesse período ainda exercem influências marcantes na atualidade.

No final do século XVIII, após a Revolução Francesa, no contexto da crescente urbanização dos países europeus e consolidação do sistema fabril, aparece, com força crescente, a explicação social na causalidade das doenças (causação social), relacionando-as com as condições de vida e de trabalho das populações. Nesse cenário e por meio do desenvolvimento das ciências sociais, surge a teoria social da medicina (o termo Medicina Social é datado de 1848), em que as condições sociais e econômicas ganham significativa importância quanto aos impactos provocados sobre a saúde e a doença. Os programas de reforma da saúde abarcam medidas sanitárias e de legislação trabalhista (Gutierrez \& Oberdiek, 2001; Laurell, 1983). Com as descobertas bacteriológicas, em meados do século XIX, a doença passa a ter seu agente etiológico (teoria unicausal) e, com isso, as concepções sociais (multicausais) são descartadas, liberando a medicina dos complexos determinantes econômicos, sociais e políticos. Decorrente da concepção unicausal, a saúde passa a ser entendida como ausência de doença, ou seja, ausência de um agravo causado por um germe. Frente a essas novas evidências, ocorreu um esforço acadêmico direcionado à mudança do ensino médico. Dentre os projetos de reformulação, sobressaiu-se o Relatório Flexner, de 1910, que colocou ênfase na pesquisa biológica e na especialização. O modelo flexneriano, presente até os dias de hoje, caracteriza-se pelo biologicismo, individualismo e especialização e fundamenta a prática sanitária curativista, biomédica, indivíduo-centrada (Santos \& Westphal, 1999).

A teoria unicausal torna-se insuficiente no início do século $X X$, quando, por meio de um processo denominado Revolução Vital, houve uma mudança no quadro de saúde da população caracterizada pela diminuição da mortalidade (pelo controle das doenças infecto-contagiosas) e aumento da morbidade (predominância de doenças crônico-degenerativas). Foi exatamente pelo sucesso do modelo unicausal em controlar as doenças que de fato tinham um agente etiológico (doenças infecto-contagiosas), combinado com sua insuficiência em atender a todas as demandas complexas (multicausais, como as doenças crônico-degenerativas e o sofrimento psíquico), que ocorreu essa mudança no quadro de saúde da população (Singer, Campos, \& Oliveira, 1978).

Com esse cenário, tem-se o nascimento da multicausalidade moderna. A partir da década de sessenta, em meio à crise econômica e política, com a diminuição de gastos sociais do Estado, os altos custos e baixa eficácia da medicina curativista/hospitalar e a limitação dos modelos dominantes em explicar os diferenciais de saúde-doença entre os grupos sociais, surge o modelo da determinação social da doença. Este modelo busca expressar a unidade do processo saúde-doença, a sua historicidade, bem como seu caráter biológico e social reconhecendo a especifi- 
cidade de cada um e analisando a relação que conservam entre si (Gutierrez \& Oberdiek, 2001; Laurell, 1983).

\section{Transformação da ciência}

Como mencionado, as concepções sobre saúde e doença estão correlacionadas às práticas de saúde. A produção de conhecimento científico, que sofre influência e também influencia tais concepções, fundamenta e consolida as práticas profissionais de saúde. Assim, é importante apresentar, também, um breve resgate do curso da ciência, de forma que se possa contextualizar, epistemologicamente, as concepções e práticas de saúde atuais.

Cabe pontuar que, quando se fala de "transformação da ciência", ou de "mudança de paradigma da ciência", não se trata de um curso histórico linear, muito menos do surgimento de "algo novo" que veio substituir "algo ultrapassado". Para esclarecer essa questão, vale resgatar o conceito de paradigma de Thomas Kuhn, compreendido como um conjunto de premissas, de pressupostos compartilhados socialmente e que orientam o modo das pessoas compreenderem as situações, de se colocarem no mundo, seja no cotidiano de suas ações - na vida pessoal/profissional - ou para estudar um fenômeno e produzir conhecimento (Kunh, 1991).

Eventualmente, esse paradigma se torna inapropriado por diversas razões, em especial, razões sociais. Surge então outro novo, que não está necessariamente relacionado ao anterior. É, simplesmente, o paradigma seguinte, que estabelece um conjunto de condições novas, define um mundo diferente e introduz um novo conjunto de problemas. $\mathrm{Na}$ sua forma extrema, o argumento de Kuhn sugere que quase não há relação entre paradigmas e que não se pode utilizar um paradigma para avaliar outro, uma vez que respondem a sistemas de valores diferentes (Wigley, 1996).
No contexto deste artigo, o que se pretende ressaltar são as mudanças de paradigma da ciência, em especial entre os séculos XVIII e $\mathrm{XX}$, e as implicações para as concepções e práticas de saúde atuais e para atuação do psicólogo no SUS.

Um forte marco do avanço da ciência se deu nos séculos XVII e XVIII, com Descartes, Newton, John Locke e Adam Smith, fundadores do lluminismo, movimento que, com ideias que derrubaram o Estado Absolutista, lançou as bases para o racionalismo e mecanicismo. Pode-se destacar como pressupostos epistemológicos dessa ciência moderna (tradicional): a simplicidade, a estabilidade e a objetividade (Vasconcellos, 2003).

O pressuposto da simplicidade se remete à crença de que é preciso separar o objeto em partes para entender o todo, daí decorre, entre outras coisas, a atitude de análise e a busca das relações causais lineares. O pressuposto da estabilidade se baseia na crença de que o mundo é estável. Ligadas a esse pressuposto estão as crenças na determinação e previsibilidade dos fenômenos, e por consequência, na reversibilidade e controlabilidade. E o pressuposto da objetividade reside na crença de que existe uma realidade independente do observador e que é possível e indispensável ser objetivo (neutro), como critério de cientificidade, na constituição do conhecimento dito verdadeiro (Vasconcellos, 2003).

A ciência moderna, o paradigma dominante, vem passando por uma crise profunda e irreversível, fruto da revolução científica iniciada com os físicos Einstein (com o conceito de relatividade), Heisenberg (com o princípio da incerteza, demonstrando a interferência do observador na observação/medição de um objeto), dentre outros. Nessa revolução científica, as leis da física assumiram caráter probabilístico e a hipótese de determinismo mecanicista foi inviabilizada, uma vez que a totalidade do real não se reduz à soma das partes, evidenciando-se, ainda, a complexidade da distinção 
sujeito/objeto. Mais recentemente, sobretudo nas três últimas décadas do século XX, somam-se as contribuições de diversos outros cientistas por meio de conceitos e teorias que se colocaram como condições da crise do paradigma dominante, dentre os quais se destacam: o químico russo llya Prigogine, o físico e ciberneticista austríaco Heins Von Foster, o biofísico francês Henri Atlan e os biólogos chilenos Humberto Maturana e Francisco Varela. Realizando estudos e pesquisas em conformidade com o paradigma tradicional, os cientistas encontraram resultados que lhes mostraram os limites desse paradigma. Viram irreversibilidade e incontrolabilidade em alguns processos físicos, como os fenômenos do calor; reações de sistemas físico-químicos que operam longe do equilíbrio (quando as flutuações podem ser amplificadas e o sistema evolui por meio de saltos qualitativos) e determinação histórica no funcionamento de estruturas dissipativas químicas (Aun, Vasconcelos, \& Coelho, 2005; Vasconcellos, 2003).

Essas teorias culminaram em uma nova concepção de matéria e natureza e fizeram parte de um movimento convergente, sobretudo a partir de meados dos anos setenta, que atravessaram as várias ciências, inclusive as ciências sociais. Esse movimento trouxe inovações teóricas que propiciaram uma profunda reflexão epistemológica sobre o conhecimento científico. As leis assumem caráter probabilístico, aproximativo e provisório. Na biologia, onde as interações entre fenômenos e formas de auto-organização são mais visíveis, a noção de lei foi sendo substituída pelas noções de sistema, estrutura, modelo e processo. Os objetos passam a ter fronteiras cada vez menos definidas, a tal ponto que os objetos em si são menos reais que as relações, em teias complexas, entre eles (Vasconcellos, 2003; Santos, 2006).

Dessas inovações teóricas surgem conceitos importantes como a circularidade e a recursividade. O primeiro vai além da causalidade linear por se referir a um sistema autorregulador. Já a recursividade se refere a uma re- visão das noções de produto e produtor. Trata-se de uma causalidade complexa que pode ser representada por uma espiral em que o produto de uma ação retorna a situação que Ihe produziu, reforçando-o, quer dizer, gerando processo de produção (Vasconcellos, 2003).

Tudo no universo está em relação por meio de um emaranhamento de ações, interações e retroações, esse é um dos princípios sobre os quais Morin (1996a) discorre sobre a epistemologia da complexidade. Segundo o autor, ao adotar o ponto de vista da complexidade, sabe-se que é impossível um ponto de vista onisciente e que o caminho possível é a construção de metapontos de vista - limitados e frágeis - requisito que diferencia o pensamento simples, que acredita em verdades absolutas (em realidade independente do observador) e o conhecimento complexo que aponta para a necessidade da curva auto-observável do observador-conceituador sobre si mesmo, o que inclui autocrítica.

Ao discorrer sobre a revolução paradigmática, Morin (1996a) afirma que está acontecendo, mas que é difícil discerni-la, pois uma grande virada nas premissas do pensamento necessita de muito tempo, trata-se de uma revolução difícil, lenta e múltipla. Santos (2006) faz um delineamento do paradigma emergente ou pós-moderno, mas não chega a nomeálo, nem aponta epistemologias que poderiam assumir esse caráter. Afirma que a crise do paradigma dominante emite sinais que permitem apenas uma especulação acerca do paradigma que emergirá do período de revolução científica, mas que este, apresentará distinções básicas do paradigma dominante.

Semelhante ao delineamento feito por Santos, a respeito da revolução científica e as condições que preparam terreno para o surgimento do paradigma emergente, Vasconcellos (2003) segue o percurso da ciência e vai além, afirmando ser o pensamento sistêmico o novo paradigma da ciência. O pensamento sistêmico, segundo a autora, assume um caráter novo paradigmático por meio do avanço 
nas três dimensões epistemológicas fundamentais: do pressuposto da simplicidade para o pressuposto da complexidade (buscando a contextualização dos fenômenos e reconhecendo a causalidade recursiva); do pressuposto da estabilidade para o da instabilidade (entendendo que o mundo está em processo dinâmico de constantes transformações e a consequente imprevisibilidade dos fenômenos); e do pressuposto da objetividade para o pressuposto da intersubjetividade (reconhecendo que não há uma realidade independente do observador, que o conhecimento científico é construção social, em espaços consensuais, por diferentes sujeitos/observadores).

$\mathrm{Na}$ apresentação do pensamento sistêmico como o novo paradigma da ciência, Vasconcellos (2003) sintetiza os principais pontos da mudança paradigmática da ciência de uma forma clara e didática. Contudo, vale ressaltar que não se trata de uma ciência "nova" propriamente dita, uma vez que referências aos pressupostos da complexidade, instabilidade e intersubjetividade já emergiram de pensadores céticos desde o século VI a.C., como pontua Glasersfeld (1996). Segundo este autor, os céticos sustentavam que não há como afirmar se o que vemos é correto, "já que cada vez que se contempla o mundo externo, o que vemos é visto de novo, através de nosso sistema sensorial e de nosso sistema conceitual" (p. 77). Essa concepção nos remete hoje ao pensamento construtivista e ao filósofo italiano Giambattista Vico (considerado o primeiro construtivista) que, no início do século XVIII, afirmou em sua tese que "os seres humanos só podem conhecer o que eles mesmos criaram" (Glasersfeld, 1996, p. 78).

O que há de novo então? Pode-se dizer que novo é o reconhecimento crescente desses pressupostos epistemológicos pelas pessoas, pelos profissionais de diversas áreas, pelos cientistas, pela academia em geral. Nova é a abertura deste "mundo oficial da ciência" aos pressupostos da complexidade, instabilidade e intersubjetividade. Morin (1996b), ao falar da nova ciência, diz que "estamos numa época onde uma nova cientificidade permite considerar coisas que a antiga não considerava, mas as velhas concepções persistem em enormes setores do pensamento e da consciência de muitos cientistas" e que devemos lutar contra a disjunção e a favor da conjunção, estabelecendo ligação entre coisas que estão separadas.

Vasconcellos (2003) afirma que é no cientista que se produz a mudança de paradigma, que é ele e não a ciência, que pode, ou não, tornar-se novo paradigmático. Ademais, ressalta que a mudança de paradigma não implica na destruição ou substituição do paradigma tradicional, isso porque o pensador sistêmico foca nas relações e, naturalmente, tendo ultrapassado uma forma de pensar disjuntiva e adotado a lógica aditiva, ele pensará a articulação. Ao ter-se tornado novo-paradigmático, o cientista resgata e integra a ciência tradicional, porém tendo um novo olhar sobre ela.

Santos (2006) aponta que a reflexão epistemológica se mostra muito mais avançada e sofisticada que a prática científica, de forma que se evidencia uma fase de transição e insegurança. Cabe lembrar que essas palavras procederam de um discurso do autor realizado em meados da década de oitenta e ainda hoje, embora o paradigma emergente se apresente de forma mais concreta, a prática científica mostra-se fortemente atrelada aos pressupostos da ciência tradicional.

Para Rifkin e Howard (1980, citados por Vasconcellos, 2003) a geração atual, nutrida pelo paradigma tradicional da ciência e convivendo com o novo paradigma apenas emergente, questiona suas crenças anteriores, mas se mostra incapaz de abandonar completamente a visão de mundo em que foi condicionada e não se sente totalmente confortável com a nova visão para articulá-la com as rotinas diárias. Contudo, para as próximas gerações, o novo paradigma da ciência será sua segunda natureza. As pessoas não pensarão sobre ele, mas viverão por meio dele e como por muito 
tempo as pessoas foram inconscientes do domínio do paradigma tradicional, também elas, das próximas gerações, não perceberão, conscientemente, o domínio do novo paradigma sobre si.

\section{Atenção à saúde atual - Transição de modelos}

Esta fase de transição paradigmática da ciência pode ser visualizada claramente na área da saúde, onde, embora se tenha um modelo abrangente de compreensão (o modelo da produção social da saúde, que busca abarcar a complexidade do processo saúdedoença), a formação científica e as práticas profissionais nessa área ainda são, predominantemente, pautadas no paradigma tradicional da ciência, por meio do modelo hegemônico da atenção biomédica: o modelo flexneriano.

O modelo flexneriano reflete uma visão racionalista por meio da dicotomia mentecorpo; mecanicista, reducionista e determinista, buscando o conhecimento aprofundado do funcionamento das partes do corpo, formando especialistas, culminando na desumanização das práticas de saúde. A fragmentação do conhecimento em disciplinas diversas possibilitou um grande avanço dos saberes, contudo, paradoxalmente, o conhecimento fragmentado dificulta a compreensão do todo. A falência desse modelo se expressa no agravamento dos problemas de saúde da população e na incapacidade da ciência, das instituições e da sociedade de responderem de forma eficiente a esses (Gomes, 1997; Spink, 2003).

Não se trata aqui de denegrir o modelo flexneriano, mas simplesmente de contextualizar suas bases epistemológicas e pontuar que, na sua concepção, há mais de cem anos, este modelo veio responder às demandas sociais daquela época (Pagliosa \& Da Ros, 2008). Trata-se de refletir sobre seus pressupostos e sua aplicabilidade no contexto atual.
Assim como a ciência em geral teve um grande avanço por intermédio do paradigma tradicional, na área da saúde, o modelo flexneriano de ensino propiciou um grande avanço teórico e tecnológico fundamental para a atualidade. Além disso, assim como a ciência tradicional encontrou seu limite por meio de seu próprio desenvolvimento, o modelo flexneriano também esbarrou em suas limitações a partir do momento em que se mostrou insuficiente para responder aos problemas de saúde da população. Uma limitação do seu conceito de saúde, de produção de conhecimento e das possibilidades de intervenção: uma limitação epistemológica.

A construção de um novo modelo e de um novo sistema de saúde que atenda às necessidades de saúde da população implica, portanto, em uma mudança epistemológica que, no contexto desta discussão, pode ser dividida em três categorias fundamentais: da concepção de saúde; do paradigma sanitário e da prática sanitária (Mendes, 1996; Santos \& Westphal, 1999).

No modelo flexneriano, pautado na ciência tradicional, saúde é entendida como ausência de doença e as práticas de saúde são voltadas à prevenção e ações curativo-reabilitadoras. Trata-se, portanto, de uma concepção negativa de um modelo que encontrou sua limitação por não conseguir responder à mudança no quadro de saúde da população. Surgem, então, novas concepções que relacionam saúde com condições de vida. A constatação de determinantes mais gerais da saúde foi o pano de fundo para a Organização Mundial da Saúde (OMS) realizar a Conferência Internacional pela Promoção da Saúde, no Canadá, em 1986, onde foi subscrita por 38 países a Carta de Ottawa, a qual apresentou a paz, educação, habitação, renda, ecossistema saudável, conservação dos recursos, justiça social e a equidade como requisitos fundamentais para a saúde. Desde então, a promoção da saúde passou a ser considerada cada vez mais nas políticas públicas (Mendes, 1996). 
A mudança de concepção que deve ser concretizada, portanto, é de uma concepção negativa de saúde para uma concepção positiva, vista como resultado de um processo de produção social que expressa a qualidade de vida da população. Não se fala, portanto, de saúde e doença como opostos, mas como um processo: o processo saúde-doença.

Atreladas a essa mudança de concepção vêm as mudanças no paradigma sanitário e na prática sanitária. O paradigma flexneriano, que tem por base os pressupostos da ciência tradicional (simplicidade, estabilidade e objetividade) privilegia o diagnóstico e a terapêutica e sustenta a prática sanitária da atenção curativa e indivíduo-centrada. O novo paradigma sanitário tem como fundamento a teoria da produção social da saúde, que busca uma compreensão contextualizada, identificada com os pressupostos da ciência novo-paradigmática (complexidade, instabilidade e intersubjetividade) e que requer, portanto, conhecimento e prática interdisciplinar e intersetorial. A prática de saúde referenciada por um conceito positivo de saúde e pelo paradigma da produção social é a vigilância da saúde. Esta compreende ação integral sobre os diferentes momentos do processo saúde-doença em três grandes ações: promoção da saúde; prevenção de doenças e atenção curativa (Mendes, 1996; Santos \& Westphal, 1999).

Neste percurso da transformação da ciência e transição paradigmática, revela-se a base epistemológica das diretrizes do SUS. Desde a concepção positiva de saúde, entendida como um processo complexo relacionado à qualidade de vida, até as diretrizes voltadas para a mudança de modelo de atenção: de uma atenção biomédica, curativa, individuo-centrada, para um modelo de vigilância da saúde em uma rede de atenção.

Para abarcar a complexidade da atenção integral à saúde, a legislação do SUS preconiza a atuação interdisciplinar e intersetorial e elege a Atenção Básica como referência e organizadora de toda a rede. Por meio da Estratégia de Saúde da Família (ESF), a Atenção Básica tem a função primordial de concretizar essa mudança de modelo de atenção preconizada pelo SUS (Brasil, 1998).

\section{Implicações da transformação da ciência para a Psicologia}

O movimento da revolução científica, sobretudo nas três últimas décadas do século $X X$, trouxe inovações teóricas que desencadearam uma profunda reflexão epistemológica sobre o conhecimento psicológico com importantes implicações no papel do psicólogo, na sua forma e contexto de atuação. Assim como a ciência em geral se encontra em um período de transição, caracterizado pela coexistência da ciência tradicional e novo-paradigmática, na Psicologia, atualmente, são encontradas linhas de pensamento fortemente pautado na ciência tradicional e outras com pressupostos epistemológicos da ciência novo-paradigmática.

A Psicologia na ciência tradicional apresenta-se com teorias e práticas pautadas pelos parâmetros de métodos lógicos e empíricos que possam resultar na descoberta de leis gerais do comportamento, correspondentes à realidade criteriosamente observada e confirmada pela replicação dos resultados de observações cientificamente obtidas. Sob a perspectiva da objetividade, o universo psicológico é concebido como passível de ser conhecido sem qualquer interferência do observador e do ato de observar. Como consequência, as pessoas e suas experiências foram objetificadas e padronizaram-se descrições e critérios diagnósticos (em manuais como o Diagnostic and Statistical Manual of Mental Disorders - DSM), consideradas descrições reais dos problemas mentais, uniformizando pessoas e contextos. Pautado no pressuposto da estabilidade, sustenta-se a crença em métodos padronizados de tratamento dos problemas humanos, por meio de procedimentos replicáveis, apoiados em 
resultados predizíveis e efetivos para pessoas em geral - incluídas nos seus rótulos (Grandesso, 2000).

Em todas as psicologias tradicionais subjetivistas e essencialistas, como os movimentos fenomenológicos, introspectivo, psicodinâmico e as terapias psicanalíticas e humanísticas, tinha-se a convicção do self como uma entidade abstrata, diferenciada e separada das restantes construções psicológicas. Conhecer, examinar o self, foi uma presunção essencialista central em grande parte da história da psicoterapia (Goolishian \& Anderson, 1996).

Nas teorias psicológicas tradicionais, de forma geral, o problema era compreendido como expressão de um defeito psíquico estrutural ou de um defeito familiar estrutural; e a terapia tinha a função de restaurar a ordem, o funcionamento do sistema defeituoso. Isso porque as famílias eram vistas como máquinas homeostáticas e o terapeuta assumia o papel de reparador do sistema em disfunção que estabelecia um diagnóstico, meta e técnicas de intervenção para a mudança. Esses modelos refletem o pensamento positivista que coloca o profissional na posição de expert, localizado fora do sistema, detentor de um conhecimento adquirido pela observação neutra (Grandesso, 2000).

Conforme essa epistemologia foi sendo questionada, novos modelos teóricos foram desenvolvidos trazendo metáforas mais úteis para as práticas sistêmicas. Os sistemas familiares e sociais deixam de ser concebidos como estruturas mecânicas coisificadas e passam a ser compreendidos como sistemas intersubjetivos compostos por agentes conscientes, intencionais que se cocriam a si mesmos e a seu entorno em uma permanente interação comunicativa e construção de significados. Ocorre uma mudança de foco das teorias clínicas do indivíduo para os sistemas humanos, do intrapsíquico para o inter-relacional (Goolishian \& Anderson, 1996; Grandesso, 2000).
Trata-se de uma nova maneira de descrever explicar, localizar e tratar os problemas. A investigação psicológica não pode mais assentar-se na observação neutra e fidedigna, mas sim nas múltiplas e contextualizadas convenções da linguagem, com um amplo horizonte de possibilidades para as suas construções (Gergen, 1985). Aqui se visualiza a passagem dos pressupostos da simplicidade e objetividade da ciência tradicional para os pressupostos sistêmicos da complexidade e intersubjetividade. O psicólogo passa a valorizar o singular contextualmente situado em vez das leis gerais; antes de procurar pelos fatos ele busca os significados; passa da posição de expert para facilitador e entra no sistema passando a fazer parte deste. No lugar de intervir, ele coparticipa do sistema terapêutico atuando para uma transformação coevolucionária, trabalhando com a imprevisibilidade uma vez que os sistemas produzem suas próprias mudanças (Grandesso, 2000).

Em uma perspectiva pós-moderna, portanto, o self passa a ser concebido como uma expressão da capacidade para a linguagem e a narração, no sentido de que os seres humanos sempre contaram coisas entre si e escutaram o que os demais contavam e que a compreensão de si se dá a partir das narrações relatadas mutuamente. Assim, as pessoas, em uma espécie de escolha seletiva dos acontecimentos da vida, dão sentido às suas experiências e constroem seu sentido de self. São, portanto, coautoras de uma narrativa em permanente mudança que se transformam nelas próprias. As histórias têm um efeito concreto para as pessoas, não só de organizar a compreensão de seu passado, mas também de modelar suas vidas, sua situação atual e seu futuro possível (Gergen, 1985; Goolishian \& Anderson, 1996; Grandesso, 2000; Schnitman \& Fuks, 1996).

Isso faz com que a natureza do self e da subjetividade se convertam em fenômenos intersubjetivos, produto das narrações das histórias por meio de uma rede de práticas sociais, das conversações: "não somos mais 
que coautores das identidades que construímos narrativamente. Somos sempre tantos selves, tantos si mesmos potenciais quanto aqueles que estão contidos nas conversações dos narradores criativos" (Goolishian \& Anderson, 1996, p.195).

Com o abandono da perspectiva universal e essencialista de self, que passa a ser compreendido como fenômeno intersubjetivo por meio da metáfora do self como processo, a terapia assume uma perspectiva de restauração e de apropriação de um lugar - o do sujeito em contexto - do qual se pode operar sobre as próprias circunstâncias na dissolução de problemas. Uma prática social que oferece às famílias, casais, pessoas ou comunidades uma oportunidade para envolver-se ativamente na construção de sua própria realidade existencial. Trata-se de um processo que implica em responsabilidade e liberdade em que se promove a restauração de um circuito recursivo: apropriação-intenção-ação-reflexão existencial, para atuar competentemente sobre os dilemas problemáticos e a incerteza da novidade (Schnitman \& Fuks, 1996).

Assim, na visão pós-moderna, a terapia não busca solução do problema, mas o restabelecimento do sentido de agenciar, que é paralelo ao desenvolvimento de novas narrativas. Ademais, se a experiência terapêutica for vivida como exitosa, o que a pessoa experimenta então é uma sensação de liberdade, de que pode agir por si mesma (Goolishian \& Anderson, 1996).

O sistema terapêutico passa a ser definido por todos os envolvidos em conversação, em uma dinâmica relacional, em torno dos significados compartilhados nos quais residem os problemas pelos quais as pessoas buscam ajuda. O psicólogo utiliza-se a si mesmo no sistema terapêutico com o fim de abrir novas possibilidades por meio da construção de um contexto conversacional para uma recriação colaborativa que permita às pessoas interrogar-se, desafiar e desligar-se de histórias saturadas de problemas e trabalhar na geração e recuperação de narrativas alternativas, experimentadas como libertadoras e transformadoras que lhes possibilitem a construção de um novo presente que seja mais tolerável, coerente e contínuo do que permitiam as narrações anteriores (Grandesso, 2000; Moré \& Macedo, 2006; Schnitman \& Fuks, 1996).

Nesse contexto conversacional terapêutico, Cecchin (1996) acrescenta a curiosidade como uma posição terapêutica que dá oportunidade para a construção de novas narrativas e formas de ação. Vários autores ressaltam, ainda, a importância de uma postura de não saber, pois, se as perguntas partem de uma perspectiva de um saber prévio, ou seja, de teorias ou compreensões pessoais do profissional, tudo o que ele irá apreender serão suas próprias narrativas (Anderson \& Goolishian, 1998; Cecchin, 1996; Schnitman \& Fuks, 1996).

Isso implica na questão do uso de modelos teóricos e técnicas. Como não se trabalha na elaboração de diagnósticos essencialistas e intervenções corretivas, as teorias e as técnicas do psicólogo mostram-se úteis à medida que permitem que a conversação se abra para novos significados mais libertadores. Ter uma teoria, nesse sentido, não quer dizer obedecer a uma teoria em particular, mas valer-se de referenciais significativos que ofereçam uma conexão com a experiência da família e o uso de técnicas serve para inclusão do outro e a abertura de possibilidades de boas conversações. Assim, o psicólogo organiza suas teorias e deriva práticas em um interjogo recursivo em que os problemas são vistos não como coisas a serem eliminadas, mas como dilemas resultantes da participação dos indivíduos, interativa e discursiva, em seus contextos sociais (Grandesso, 2000; Moré \& Macedo, 2006).

Ao assumir um novo enfoque para compreender o comportamento humano e seus sintomas como produto das inter-relações do sistema, a atenção passa a ser voltada para a comunicação e o comportamento de 
todos os membros envolvidos no sistema, nos elos de recursividade entre eles. Com isso, o psicólogo estende o território da terapia sistêmica, originalmente uma terapia de família como um sistema, para além dessas fronteiras, ao incluir o indivíduo, as comunidades e outras organizações sociais, envolvidas em uma trama significativa (Aun el al., 2005; Grandesso, 2000).

Outra importante implicação da transição paradigmática na prática profissional diz respeito à passagem de uma ética normativa para uma ética das relações, da inclusão, da confirmação do outro como coconstrutor do sistema terapêutico, tanto das pessoas envolvidas com a demanda como de outros profissionais, que implica na necessidade de abertura para a interdisciplinaridade. Pois, na medida em que se considera o processo terapêutico como processo de coconstrução, todos os envolvidos passam a ser responsáveis, portanto, eticamente implicados, sendo este o caminho para atingir a transdisciplinaridade. Já a dita neutralidade passa a ser relacionada à capacidade do profissional de promover a participação de todas as pessoas envolvidas, dando voz às diferentes partes (Moré \& Macedo, 2006).

\section{Reflexões sobre a atuação do psicólogo no SUS}

A atuação do psicólogo nos serviços de saúde fundamenta-se, sobretudo, pelo princípio da integralidade. Para cuidar da saúde de forma integral, torna-se imprescindível que, sobretudo, no primeiro nível de atenção, haja equipes interdisciplinares e que desenvolvam ações intersetoriais. O psicólogo, nesse contexto, oferece uma importante contribuição na compreensão contextualizada e integral do indivíduo, das famílias e da comunidade (Böing \& Crepaldi, 2010).

Desde as primeiras incursões de psicólogos no sistema público de saúde, estudos se propuseram a discutir a efetividade de seus padrões de atuação e constataram a predo- minância de uma atenção curativa, individual e ineficiente. Assim como o modelo flexneriano predominou na formação e na prática médica, a Psicologia também assumiu, por muito tempo, como paradigma hegemônico da profissão, um modelo curativo e assistencialista voltado para o setor dos atendimentos privados. A formação profissional veio direcionando o psicólogo para modelos de atuação bastante limitados e insuficientes em lidar com a demanda da clientela e das instituições de saúde, inclusive de adaptar-se às dinâmicas condições de perfil profissional exigidas pelo SUS (Dimenstein, 2001; Oliveira et al., 2005).

No cenário atual, caminhando para uma efetiva vigilância da saúde, ainda se encontram, fortemente presentes, concepções e práticas do modelo tradicional. A mudança de modelo de atenção à saúde requer, do psicólogo, uma atuação interdisciplinar e práticas específicas da área mais adequadas ao contexto da saúde coletiva (Böing, Crepaldi, \& Moré, 2009).

O conhecimento e a prática interdisciplinar surgem como alternativas de se promover a inter-relação entre as diferentes áreas de conhecimento, entre diferentes profissionais e entre eles e o senso comum, tornando-se uma necessidade real do profissional de saúde para uma atenção integral que abrange a complexidade do processo saúde-doença. Não se trata de uma unificação dos saberes, nem de uma busca do consenso, mas relaciona-se ao pensamento divergente que requer criatividade e flexibilidade, princípio da máxima exploração das potencialidades de cada ciência e da compreensão de seus limites (Gomes, 1997).

A prática interdisciplinar promove mudanças estruturais, gerando reciprocidade, enriquecimento mútuo, com uma tendência a horizontalização das relações de poder entre os campos implicados. Inicia-se, portanto, por uma atitude novo-paradigmática, interdisciplinar, em que o profissional deve renunciar o status e a onipotência que sua especialidade 
Ihe confere e exercitar constantemente a humildade, condição necessária para uma postura de coconstrução. Não anula nem desvaloriza as especialidades, pois reconhece que elas constituem o cenário no qual ela se produz. A saúde é vista como ponto de partida e de chegada para a intervenção profissional, que se torna ampla e contextualizada, possibilitando uma compreensão das implicações sociais de sua prática para que esta possa se tornar realmente um produto coletivo e eficaz (Gomes, 1997; Moré, 2001; Vasconcelos, 2002).

Nesse contexto, a atuação do psicólogo na saúde pública se configura em uma prática de clínica ampliada, ou seja, uma prática clínica em espaços públicos não usuais, compreendendo seres humanos em seus contextos (Moré \& Macedo, 2006). Essa atuação requer do psicólogo estar preparado para trabalhar com pessoas em diferentes fases do ciclo de vida e com proveniências sociais e culturais muito diversas.

Uma descrição mais detalhada e discussão de práticas sistêmicas na atenção básica à saúde podem ser encontradas em outro artigo, específico desta temática (Böing, Crepaldi, \& Moré, 2009). Cabe destacar, ainda, que a postura novo-paradigmática que leva o psicólogo a rever e contextualizar sua prática, por si só, não basta para uma atuação condizente à mudança de modelo de atenção preconizada pelo SUS. Além disso, é crucial que o psicólogo tenha condições reais de trabalho que permitam o contato cotidiano com as pessoas, seus contextos de vida e com os demais profissionais de saúde. Outro sim, essas condições devem ser garantidas pelas políticas e pelos gestores da saúde pública. Contudo, infelizmente, a configuração atual das políticas públicas de saúde não oferece condições reais para a atuação interdisciplinar do psicólogo na saúde pública, em especial, na atenção básica (Böing \& Crepaldi, 2010). Nesse sentido, a mudança de modelo de atenção requer uma postura novo-paradigmática de todos os atores envolvidos: dos profissionais de saúde em geral, dos psicólogos, de seus representantes, dos gestores e dos cidadãos.

\section{Considerações finais}

A reflexão epistemológica das diretrizes do SUS e das implicações da mudança paradigmática da ciência para a Psicologia teve como foco, neste artigo, a atuação do psicólogo na saúde pública. Contudo, ressalta-se que esta reflexão é válida e pode ser estendida a todos os demais profissionais de saúde. Conceitos como integralidade da atenção, interdisciplinaridade e intersetorialidade só serão efetivamente incorporados no cotidiano das práticas de saúde quando os profissionais compreenderem a dimensão epistemológica desses construtos. É nas pessoas que deve acontecer a mudança de paradigma. Quando os profissionais forem capazes de discernir a origem epistemológica de suas concepções e teorias, tornar-se-ão mais livres para contextualizar e flexibilizar suas práticas. A mudança de modelo de atenção e a efetiva consolidação do SUS dependem, em grande parte, dessa compreensão e de reais mudanças nas concepções, na postura e nas práticas dos profissionais e gestores da saúde.

Cabe ressaltar que essas mudanças de concepções, postura e práticas implica uma trama complexa de inúmeros fatores relacionados à efetiva consolidação do SUS. Um importante fator é o papel das universidades na formação de recursos humanos em saúde. Contudo, até o final da década de 1990, praticamente não houve avanço nas discussões sobre a necessidade do desenvolvimento do trabalho em saúde e o setor educacional manteve-se desvinculado da reorganização dos serviços, da redefinição das práticas de atenção e dos processos de reforma (Pagliosa \& Da Ros, 2008). O Estado lançou programas visando ao redirecionamento da formação dos profissionais de saúde para atuação no SUS, como o Pró-Med e, em seguida, o PróSaúde (Programa Nacional de Reorientação da Formação em Saúde), mas ainda assim, eram voltados apenas para os profissionais 
tradicionais da saúde, mantendo o médico como figura central. Apenas em 2007, o Pró-Saúde foi ampliado para os demais cursos de graduação da área da saúde, além dos cursos de Medicina, Enfermagem e Odontologia, visando a incentivar transformações do processo de formação, de geração de conhecimentos e de prestação de serviços à comunidade para abordagem integral na atenção à saúde.

Há, ainda, muita contradição entre o discurso sobre o SUS e a prática. Busca-se um modelo de atenção integral à saúde, mas são poucos os profissionais que têm o privilégio de integrar uma equipe, de fato, interdisciplinar. Fala-se muito em qualidade da atenção, mas mantém-se, por exemplo, uma lógica de financiamento baseada na quantidade de procedimentos. Ainda persiste uma grande disparidade salarial entre os profissionais de saúde. Grande parte dos serviços públicos de saúde encontra-se em condições precárias de funcionamento, enquanto a mídia denuncia, diariamente, escândalos de corrupção e desvio de recursos públicos. A política preconiza a participação dos cidadãos, mas os mecanismos de controle social são boicotados pelos gestores. Além disso, existem forças políticas, econômicas e ideológicas em disputa dentro do Sistema e, muitas vezes, contrárias a este.

Esses são alguns dos inúmeros fatores que interagem recursivamente nos caminhos e descaminhos da consolidação do SUS. As reflexões propostas neste artigo tiveram por objetivo apenas sinalizar que um ponto crucial, para todas as mudanças que se fazem necessárias, é a compreensão epistemológica das diretrizes da saúde pública brasileira por todos os atores envolvidos: profissionais, gestores e cidadãos.

\section{Elisangela Böing}

Doutorado pela Universidade Federal de Santa Catarina.

Docente do Departamento de Psicologia da Universidade Federal de Santa Catarina (UFSC).

E-mail: elisangelaboing@gmail.com

\section{Maria Aparecida Crepaldi}

Pós-Doutorado pela Universidade do Québec em Montreal - UQÀM

Docente do Departamento de Psicologia da Universidade Federal de Santa Catarina (UFSC)

E-mail: maria.crepaldi@gmail.com

\section{Endereço para envio de correspondência:}

Departamento de Psicologia. Centro de Filosofia e Ciências Humanas. Universidade Federal de Santa Catarina - UFSC. Campus Universitário - Trindade - Florianópolis Santa Catarina - Brasil - CEP 88.010-970

Recebido 09/03/2013, 1a Reformulação 15/01/2014 Aprovado 04/08/2014 


\section{Referências}

Anderson, H., \& Goolishian, H. (1998). O cliente é o especialista: a abordagem terapêutica do não saber. In S. McNamee \& K. J. Gergen (Orgs.), A Terapia como Construção Social (pp. 34-49). Porto Alegre: Artes Médicas.

Andrade, S. M., Soares, D. A., \& Cordoni Jr., L. (Orgs). (2001). Bases da Saúde Coletiva. Londrina, PR: UEL.

Aun, J. G., Vasconcellos, M. J. E. de, \& Coelho, S. V. (2005). Atendimento de Famílias e Redes Sociais: fundamentos teóricos e epistemológicos. Belo Horizonte: Ophicina da Arte \& Prosa.

Böing, E., \& Crepaldi, M. A. (2010). O Psicólogo na Atenção Básica: uma Incursão pelas Políticas Públicas de Saúde Brasileiras. Psicologia: Ciência e Profissão, 30(3), 634-649. doi: http://dx.doi.org/ 10.1590/S1414-98932010000300014

Böing, E., Crepaldi, M. A., \& Moré, C. L. O. O. (2009). A Epistemologia Sistêmica como Substrato à Atuação do Psicólogo na Atenção Básica. Psicologia: Ciência e Profissão, 29(4), 828-845. doi: 10.1590/S1414-98932009000400013

Brasil, Ministério da Saúde, \& Secretaria Nacional de Assistência Social à Saúde. (1990). ABC do SUS - Doutrinas e Princípios. Brasília, DF: Secretaria Nacional de Assistência Social à Saúde.

Brasil.,Ministério da Saúde., Secretaria Nacional de Assistência Social à Saúde., \& Coordenação de Saúde da Comunidade. (1998). Saúde da Família: uma estratégia para reorientação do modelo assistencial. Brasília, DF: Ministério da Saúde.

Campos, G. W. S. (2007). Reforma política e sanitária: a sustentabilidade do SUS em questão? Ciência \& Saúde Coletiva, 12(2), 301-306. doi: 10.1590/S1413-81232007000200002

Cecchin, G. (1996). Construcionismo social e irreverência terapêutica. In D. F. Schnitman (Org.), Novos paradigmas, cultura e subjetividade. (pp. 216-224). Porto Alegre: Artes Médicas.

Dimenstein M. (2001). O psicólogo e o compromisso social no contexto da saúde coletiva. Psicologia em Estudo (Maringá), 6(2), 57-63. doi: 10.1590/S1413-73722001000200008.

Gergen, K. J. (1985). Theory of the self: Impasse and evolution. In L. Berkowitz (Org.), Advances in experimental social psychology. New York: Academic Press.
Glasersfeld, E. von. (1996). A construção do conhecimento. In D. F. Schnitman (Org.), Novos paradigmas, cultura e subjetividade. (pp. 7592). Porto Alegre: Artes Médicas.

Goolishian, H. A., \& Anderson, H. (1996). Narrativa e self: alguns dilemas pós-modernos da psicoterapia. In D. F. Schnitman (Org.), Novos paradigmas, cultura e subjetividade. (pp. 191199). Porto Alegre: Artes Médicas.

Gomes, D. C. R. (1997). Equipe de saúde: o desafio da integração. Uberlândia, MG: Editora da Universidade Federal de Uberlândia.

Grandesso, M. (2000). Sobre a reconstrução do significado: uma análise epistemológica e hermenêutica da prática clínica. São Paulo: Casa do Psicólogo.

Gutierrez, P. R., \& Oberdiek, H. I. (2001). Concepções sobre a Saúde e a Doença. In S. M. Andrade, D. A. Soares, \& L. Cordoni Jr. (Orgs.), Bases da Saúde Coletiva (pp. 1-26). Londrina, PR: UEL.

Kunh, T. S. (1991). A estrutura das revoluções científicas. São Paulo: Perspectiva.

Laurell, A. C. (1983). A saúde como processo social. In E. D. Nunes (Org.), Medicina social: aspectos históricos e teóricos (pp. 133-158). São Paulo: Global.

Mendes, E.V. (1996). Um novo paradigma sanitário: a produção social da saúde. In E. V. Mendes (Org.), Uma agenda para a saúde (pp. 233300). São Paulo: Hucitec.

Moré, C. L. O. O., \& Macedo, R. M. S. (2006). A Psicologia na Comunidade: uma proposta de intervenção. São Paulo: Casa do Psicólogo.

Moré, C. L. O. O. (2001). A representação social do psicólogo e de sua prática no espaço público-comunitário. Paidéia - Cadernos de Psicologia e Educação, 11(20), 85-98. doi: 10.1590/S0103-863X2001000200010

Morin, E. (1996a). Epistemologia da complexidade. In D. F. Schnitman (Org.), Novos paradigmas, cultura e subjetividade. (pp. 274-286). Porto Alegre: Artes Médicas.

Morin, E. (1996b). A noção de sujeito. In D. F. Schnitman (Org.), Novos paradigmas, cultura e subjetividade. (pp. 45-58). Porto Alegre: Artes Médicas. 
Oliveira, I. F., Dantas, C. M. B., Costa, A. L. F., Gadelha, T. M. S., Ribeiro, E. M. P. C., \& Yamamoto, O. H. (2005). A Psicologia, o Sistema Único de Saúde e o Sistema de Informações Ambulatoriais: inovações, propostas e desvirtuamentos. Interação em Psicologia, 9(2), 273283. doi: 10.5380\%2Fpsi.v9i2.4790

Pagliosa F. L., \& Da Ros M. A. (2008). O Relatório Flexner: para o bem e para o mal. Revista Brasileira de Educação Médica. 32(4), 492-9. doi: 10.1590/S0100-55022008000400012

Santos, B. S. (2006). Um discurso sobre as ciências (4 ed.). São Paulo: Cortez.

Santos, J. L. F., \& Westphal, M. F. (1999). Práticas emergentes de um novo paradigma de saúde: o papel da universidade. Estudos Avançados, 13(35), 71-87. doi: 10.1590/S010340141999000100007

Schnitman, D. F., \& Fuks, S. I. (1996). Metáforas da mudança: terapia e processo. In D. F. Schnitman (Org.), Novos paradigmas, cultura e subjetividade. (pp. 244-253). Porto Alegre: Artes Médicas.
Singer, P., Campos, O., \& Oliveira, E. M. (1978). Prevenir e Curar: controle social através dos serviços de saúde. Rio de Janeiro: Forense.

Spink, M. J. P. (2003). Psicologia Social e Saúde: Práticas, Saberes e Sentidos. Petrópolis, RJ: Vozes.

Vasconcellos, M. J. de. (2003) Pensamento Sistêmico: o novo paradigma da ciência. Campinas, SP: Papirus.

Vasconcelos, E. M. (2002). Complexidade e pesquisa interdisciplinar. Petrópolis, RJ: Vozes.

Wigley, M. (1996). A desconstrução do espaço. In D. F. Schnitman (Org.), Novos paradigmas, cultura e subjetividade. (pp. 152-171). Porto Alegre: Artes Médicas. 